\title{
Tolerability and efficacy of gamma knife radiosurgery on hepatocellular carcinoma with portal vein tumor thrombosis
}

\author{
Xiao-Jie Lu1,*, Jing Dong ${ }^{2, *}$, Li-Juan $\mathrm{Ji}^{3, *}{ }^{3}$, Li-Xin Xiao ${ }^{4}$, Chang-Quan Ling ${ }^{5}$ and Jun \\ Zhou' ${ }^{6}$ \\ ${ }^{1}$ Department of Gastroenterology, Shanghai East Hospital, Tongji University School of Medicine, Shanghai, China \\ 2 Outpatient Department, Zhejiang Provincial People's Hospital, Hangzhou, Zhejiang Province, China \\ ${ }^{3}$ Department of Rehabilitation, The Affiliated Huai'an Hospital of Xuzhou Medical College and The Second People's Hospital \\ of Huai'an, Huai'an, China \\ ${ }^{4}$ Department of Gamma Knife, The 411st Hospital of Chinese People's Liberation Army, Shanghai, China \\ ${ }^{5}$ Changhai Hospital of Traditional Chinese Medicine, Second Military Medical University, Shanghai, China \\ ${ }^{6}$ Department of Oncology and Hematology, Shanghai East Hospital, Tongji University School of Medicine, Shanghai, China \\ * Co-first authors
}

Correspondence to: Jun Zhou, email: zhouyishi1218@163.com

Keywords: hepatocellular carcinoma; portal vein tumor thrombosis; gamma knife; adverse events; overall survival

Received: August 14, $2015 \quad$ Accepted: September 24, $2015 \quad$ Published: October 14, 2015

This is an open-access article distributed under the terms of the Creative Commons Attribution License, which permits unrestricted use, distribution, and reproduction in any medium, provided the original author and source are credited.

\section{ABSTRACT}

This is a retrospective study on the safety and efficacy of gamma knife radiosurgery (GKR) in treating hepatocellular carcinoma (HCC) with portal vein tumor thrombosis (PVTT). Patients with confirmed HCC and PVTT were allocated into two groups based on the treatments they received (palliative or GKR). A total of 138 patients were included ( 74 in the palliative group, 64 in GKR group). No significant differences in baseline characteristics existed between the two groups. Treatmentrelated adverse events (AEs) were recorded and compared between groups. The majority of AEs were mild to moderate and subsided naturally or after medication. There was no AE-induced death. The influences of baseline characteristics and treatment options on patients' OS were analyzed. The median OS of patients in the palliative and GKR group were 3.0 months (95\% CI: 2.719-3.281) and 6.1 months (95\% CI: 4.706-7.494) respectively $(p=0.003)$. Multivariate analysis revealed that GKR treatment, performance status 0-1, Child A, smaller tumor diameter and monolobar distribution were significant favorable prognosticators. Subgroup analyses showed OS benefit of GKR regardless of PVTT location (main or branch of PVTT). In conclusion, GKR is well tolerated in selected HCC-PVTT patients and can confer OS benefit, which needs validation in future prospective studies.

\section{INTRODUCTION}

Hepatocellular carcinoma (HCC) represents the second leading cause of cancer death worldwide, with half of the cases being in China [1]. It was reported that approximately $10 \%-40 \%$ of HCC patients are diagnosed with portal vein tumor thrombus (PVTT) [2,3] and that up to $44 \%$ of HCC patients are complicated with PVTT at the time of death [4]. According to the Barcelona Clinic Liver Cancer (BCLC) classification system [5], HCC patients with PVTT are classified as advanced stage (or Stage C) and bear a rather dismal prognosis with expected median survival span of about only 2.7-3.0 months [3, 6].

Sorafenib is currently regarded as the standard treatment for HCC-PVTT patients [7, 8]. However, clinical trials $[9,10]$ showed that it can only produce 2-to-3 months of overall survival (OS) benefit in BCLC stage $\mathrm{C}$ patients. Moreover, the high price of sorafenib makes it unaffordable for many patients in the developing countries such as China. Therefore, there is an urgent need to explore alternative therapeutics for HCC patients with PVTT. 
Table 1: Baseline characteristics of patients included in this study.

\begin{tabular}{|c|c|c|c|c|}
\hline Baseline characteristics & & Palliative group $(n=74)$ & GKR group $(n=64)$ & $P$ value* \\
\hline Age & Mean \pm SD & $54.34 \pm 11.01$ & $52.83 \pm 9.53$ & 0.394 \\
\hline \multirow{2}{*}{ Gender } & Male $(\mathrm{n}=117)$ & 64 & 53 & \multirow{2}{*}{0.549} \\
\hline & Female $(\mathrm{n}=21)$ & 10 & 11 & \\
\hline \multirow{4}{*}{ Etiologies } & $\operatorname{HBV}(n=116)$ & 61 & 55 & 0.722 \\
\hline & $\operatorname{HCV}(n=7)$ & 4 & 3 & \\
\hline & Alcohol $(\mathrm{n}=10)$ & 5 & 5 & \\
\hline & Others $(\mathrm{n}=5)$ & 4 & 1 & \\
\hline \multirow{2}{*}{ Type of PVTT } & Branches of portal vein $(n=71)$ & 35 & 36 & \multirow{2}{*}{0.294} \\
\hline & Main portal vein $(n=67)$ & 39 & 28 & \\
\hline \multirow{2}{*}{ Cirrhosis } & Absent (14) & 9 & 5 & 0.573 \\
\hline & Precent (124) & 65 & 59 & \\
\hline \multirow{2}{*}{ Child-Pugh } & $\mathrm{A}(\mathrm{n}=107)$ & 54 & 53 & 0.167 \\
\hline & B7 $(n=31)$ & 20 & 11 & \\
\hline \multirow{2}{*}{ ECOG PST } & $0-1(n=99)$ & 49 & 50 & 0.121 \\
\hline & $2(n=39)$ & 25 & 14 & \\
\hline \multirow{2}{*}{ Tumor nodules } & Single $(n=65)$ & 31 & 34 & 0.187 \\
\hline & Multiple $(n=73)$ & 43 & 30 & \\
\hline \multirow{4}{*}{ Largest tumor size } & Mean \pm SD & $9.79 \pm 4.77$ & $8.14 \pm 3.73$ & 0.261 \\
\hline & $\leq 5 \mathrm{~cm}$ & 15 & 11 & 0.098 \\
\hline & $5-10 \mathrm{~cm}$ & 25 & 33 & \\
\hline & $>10 \mathrm{~cm}$ & 34 & 20 & \\
\hline \multirow{2}{*}{ Bilobar } & No $(n=83)$ & 41 & 42 & 0.221 \\
\hline & Yes $(n=55)$ & 33 & 22 & \\
\hline \multirow{2}{*}{ AFP } & $\leq 400 \mathrm{ng} / \mathrm{ml}(\mathrm{n}=49)$ & 25 & 24 & 0.649 \\
\hline & $>400 \mathrm{ng} / \mathrm{ml}(\mathrm{n}=89)$ & 49 & 40 & \\
\hline \multirow{2}{*}{ Total bilirubin } & Mean \pm SD & $1.12 \pm 0.64$ & $1.10 \pm 0.58$ & 0.552 \\
\hline & $>1.5 \mathrm{mg} / \mathrm{dl}$ & 15 & 17 & 0.302 \\
\hline \multirow{2}{*}{ Albumin } & Mean \pm SD & $34.77 \pm 4.11$ & $35.58 \pm 4.22$ & 0.258 \\
\hline & $<30 \mathrm{~g} / \mathrm{L}$ & 13 & 9 & 0.349 \\
\hline \multirow{2}{*}{ ALT } & Mean \pm SD & $44.51 \pm 19.67$ & $43.55 \pm 21.51$ & 0.274 \\
\hline & $>40 \mathrm{u} / \mathrm{L}$ & 15 & 13 & 0.995 \\
\hline \multirow{2}{*}{ AST } & Mean \pm SD & $46.27 \pm 20.80$ & $42.13 \pm 21.10$ & 0.248 \\
\hline & $>40 \mathrm{u} / \mathrm{L}$ & 17 & 11 & 0.399 \\
\hline \multirow{2}{*}{ GTT } & Mean \pm SD & $178.22 \pm 132.03$ & $182.31 \pm 158.86$ & 0.869 \\
\hline & $>50 \mathrm{u} / \mathrm{L}$ & 47 & 36 & 0.385 \\
\hline \multirow{2}{*}{ INR } & Mean \pm SD & $1.03 \pm 0.19$ & $1.06 \pm 0.21$ & 0.493 \\
\hline & $\geq 1.3$ & 5 & 5 & 0.811 \\
\hline \multirow{2}{*}{ WBC } & Mean \pm SD & $5.26 \pm 1.04$ & $5.55 \pm 1.14$ & 0.119 \\
\hline & $<4.0 \times 109 / \mathrm{L}$ & 5 & 6 & 0.571 \\
\hline \multirow{2}{*}{ HB } & Mean \pm SD & $123.9 \pm 12.02$ & $125.70 \pm 17.26$ & 0.578 \\
\hline & $<110 \mathrm{~g} / \mathrm{L}$ & 8 & 5 & 0.548 \\
\hline \multirow{2}{*}{ Platelets } & Mean \pm SD & $110.2 \pm 17.59$ & $112.05 \pm 19.66$ & 0.562 \\
\hline & $\leq 100 \times 10^{9} / \mathrm{L}$ & 21 & 19 & 0.866 \\
\hline
\end{tabular}

*: Intergroup differences in baseline characteristics were analyzed using t-test for continuous data and Chi-Square test or Fisher exact test (for small samples) for categorical variables. $P<0.05$ was considered statistically significant. TACE: transarterial chemoembolization; GKR: gamma knife radiosurgery; PVTT: portal vein tumor thrombosis; HBV: hepatitis B virus; HCV: hepatitis C virus; ECOG PST: Eastern Cooperative Oncology Group Performance status; INR: international normalized ratio; AFP: alpha fetal protein; ALT: alanine transaminase; AST: aspartate transaminase; WBC: white blood cell; Hb: hemoglobin; GGT: gamma-glutamyl transpeptidase. 
Radiotherapies have long shown promise in treating HCC patient with PVTT, such as the intraarterial injection of ${ }^{131}$ I-labeled-iodized oil [11] and the ${ }^{90}$ Y-based radioembolization [12]. Gamma knife radiosurgery (GKR) is a kind of external radiation therapy that have been reported to show favorable effects in treating brain metastases of HCC in retrospective studies [13, 14]. In a few cancer centers in China, it has been practiced for treating HCC-PVTT patients for more than ten years. Recently, our team [15] conducted a retrospective study which found that the median OS of HCC-PVTT patients receiving combined therapy of transarterial chemoembolization (TACE) and GKR was significantly longer than that of HCC-PVTT patients receiving TACE alone. However, it is still not clear whether patients receiving combined therapy lived longer as a result of therapeutic effects or whether they received more therapeutics simply because they lived longer (because of a more benign course). And it is not clear either whether the observed OS gain in the TACE plus GKR group versus TACE alone group was owing to GKR treatment per se or owing to the synergic effects of TACE and GKR. To address these questions, we conducted a separate retrospective study to investigate the safety and efficacy of GKR monotherapy on HCC patients with PVTT.

\section{RESULTS}

\section{Baseline characteristics}

During the study period, a total of $310 \mathrm{HCC}$ patients with confirmed PVTT were admitted to Changhai Hospital (Shanghai, China). According to the patient inclusion and exclusion criteria, 138 patients were included into this study finally, with 74 in the palliative group and the other 64 in the GKR group (Figure 1). No significant differences in baseline characteristics existed between the two groups (Table 1).

\section{Safety and procedure-related adverse events}

As mentioned above, clinical follow-ups (blood tests, physical examinations, etc.) in the palliative group were not as regular as in the GKR group. So, AEs data of the palliative group were incomplete. Nausea/vomiting, fatigue, abdominal pain, anorexia, radiodermatitis and transient liver function impairment were common GKRrelated AEs (Tables 2 and 3). The majority of them, however, were mild-to-moderate (grade 1-2) ones and subsided naturally or after medication. Compared with pre-procedure, there were significantly more cases of

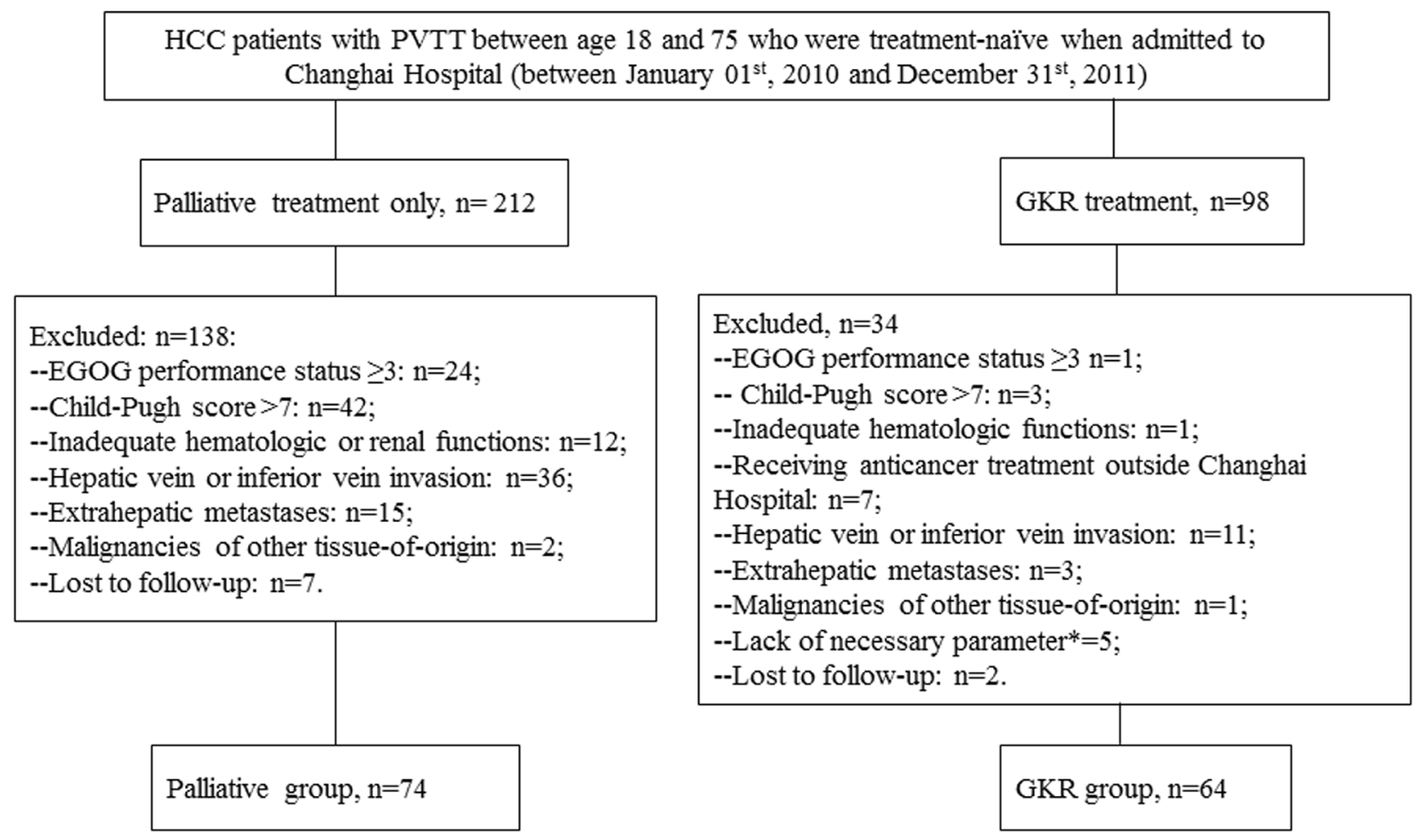

Figure 1: Flowchart of patients inclusion and exclusion. *: Referring to patients whose clinical/laboratory follow-ups were so incomplete that subsequent analyses were impossible. 
Table 2: Main procedure-related clinical adverse events by CTCAE grades

\begin{tabular}{|l|l|l|l|l|l|}
\hline CTCAE & Grade 1 & Grade 2 & Grade 3 & Grade 4 & All grades \\
\hline Abdominal pain & $12(18.75)$ & $9(14.06)$ & $2(3.13)$ & 0 & $21(32.8)$ \\
\hline Anorexia & $8(12.5)$ & $16(25)$ & 0 & 0 & $24(37.5)$ \\
\hline Ascites & $1(1.56)$ & 0 & 0 & 0 & $1(1.56)$ \\
\hline Constipation & $2(3.13)$ & $2(3.13)$ & 0 & 0 & $4(6.25)$ \\
\hline Fatigue & $8(13)$ & $5(8)$ & 0 & 0 & $13(20)$ \\
\hline Nausea/vomiting & $11(17.19)$ & $15(23.44)$ & 0 & 0 & $26(40.63)$ \\
\hline Pneumonitis & 0 & $2(3)$ & 0 & 0 & $2(3)$ \\
\hline Dermatitis & $11(17.19)$ & $5(7.81)$ & 0.00 & 0.00 & $16(25)$ \\
\hline
\end{tabular}

CTCAE: National Cancer Institute Common Terminology Criteria for Adverse Events.

Table 3: Main procedure-related laboratory adverse events by CTCAE grades

\begin{tabular}{|c|c|c|c|c|c|c|}
\hline \multirow{2}{*}{ CTCAE } & \multicolumn{2}{|c|}{ pre-procedure } & 3 months post-procedure & $\boldsymbol{p}$ value* & $\boldsymbol{p}$ value\# \\
\cline { 2 - 7 } & All grades & Grade $\geq \mathbf{3}$ & All grades & Grade $\geq \mathbf{3}$ & & \\
\hline Leukocytopenia & $6(9.4)$ & 0 & $9(14.6)$ & $3(4.7)$ & 0.375 & 0.25 \\
\hline HB & $5(7.8)$ & 0 & $3(4.7)$ & 0 & 0.5 & 1 \\
\hline Thrombocytopenia & $19(29.7)$ & 0 & $27(42.2)$ & $3(4.7)$ & 0.077 & 0.25 \\
\hline Hypoalbumin & $9(14.1)$ & 0 & $13(20.3)$ & 0 & 0.344 & 1 \\
\hline ALT/AST $\uparrow$ & $24(37.5)$ & 0 & $39(60.9)$ & $8(12.5)$ & 0.017 & 0.008 \\
\hline TB $\uparrow$ & $17(26.6)$ & 0 & $33(51.6)$ & $3(4.7)$ & 0.002 & 0.25 \\
\hline GTT $\uparrow$ & $36(56.3)$ & 0 & $39(60.9)$ & $17(26.6)$ & 0.664 & $<0.001$ \\
\hline Creatinine & 0 & 0 & $2(3.1)$ & 0 & 0.5 & 1 \\
\hline INR & $5(7.8)$ & 0 & $11(17.2)$ & 0 & 0.109 & 1 \\
\hline
\end{tabular}

*: Intragroup differences in all grades LAEs between baseline and month 3 were analyzed with Exact McNemar's test, $p<0.05$ was considered statistically significant. \#: Intragroup differences in grade $\geq 3$ LAEs between baseline and month 3 were also analyzed with Exact McNemar's test. TB: total bilirubin; ALT: alanine transaminase; AST: aspartate transaminase; INR: international normalized ratio; GGT: gammaglutamyl transpeptidase; CTCAE: National Cancer Institute Common Terminology Criteria for Adverse Events.

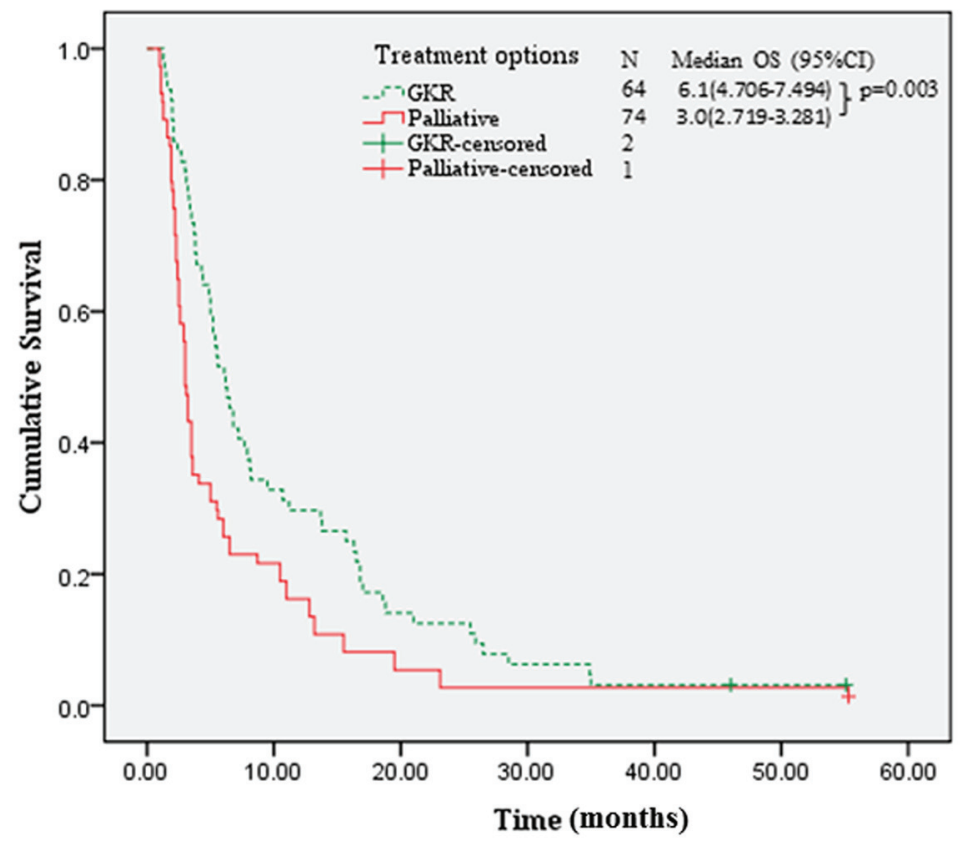

Figure 2: Kaplan-Meier survival curves of patients by treatment options. GKR: gamma knife radiosurgery. 
Table 4: Univariate and multivariate survival analyses by baseline characteristics and treatment options.

\begin{tabular}{|c|c|c|c|c|c|}
\hline & & \multicolumn{2}{|l|}{ Univariate analysis } & \multicolumn{2}{|l|}{ Multivariate analysis } \\
\hline & & $\begin{array}{l}\text { mOS }(95 \% \text { CI }), \\
\text { months }\end{array}$ & $P$ value & Hazard ratio $(95 \%$ CI) & $P$ value \\
\hline \multicolumn{2}{|l|}{ All patients } & \multicolumn{3}{|l|}{$3.9(2.931-4.869)$} & \\
\hline \multirow{2}{*}{ Age } & $<50(\mathrm{n}=50)$ & $3.6(2.677-4.523)$ & 0.45 & & \\
\hline & $\geq 50(\mathrm{n}=88)$ & \multicolumn{3}{|l|}{$4.1(2.445-5.755)$} & \\
\hline \multirow{2}{*}{ Gender } & male $(\mathrm{n}=117)$ & $3.7(2.807-4.593)$ & 0.04 & 1 & \\
\hline & female $(n=21)$ & 6.8(4.987-8.597) & & $0.765(0.438-1.335)$ & 0.35 \\
\hline \multirow{4}{*}{ Etiologies } & $\operatorname{HBV}(n=116)$ & $3.6(2.578-4.812)$ & 0.46 & & \\
\hline & $\mathrm{HCV}(\mathrm{n}=7)$ & \multicolumn{3}{|l|}{$3.7(2.642-4.953)$} & \\
\hline & $\operatorname{alcohol}(n=10)$ & \multicolumn{3}{|l|}{$4.0(2.982-4.893)$} & \\
\hline & others $(\mathrm{n}=5)$ & \multicolumn{3}{|l|}{$4.0(2.886-4.965)$} & \\
\hline \multirow{2}{*}{$\begin{array}{l}\text { Type } \\
\text { of PVTT }\end{array}$} & $\begin{array}{l}\text { branches of portal vein } \\
(\mathrm{n}=71)\end{array}$ & $6(4.761-7.239)$ & $<0.001$ & $0.887(0.573-1.372)$ & 0.6 \\
\hline & main portal vein $(n=67)$ & $3.2(2.901-3.499)$ & & 1 & \\
\hline \multirow{2}{*}{ Cirrhosis } & absent (14) & \multicolumn{3}{|l|}{$4.5(3.391-5.456)$} & \\
\hline & precent (124) & $3.4(2.333-4.456)$ & 0.16 & & \\
\hline \multirow{2}{*}{$\begin{array}{l}\text { Child-Pugh } \\
\text { score }\end{array}$} & $\mathrm{A}(\mathrm{n}=107)$ & $5.2(4.186-6.214)$ & $<0.001$ & $0.534(0.333-0.857)$ & $<0.001$ \\
\hline & B7 $(n=31)$ & \multicolumn{2}{|l|}{ 2.4(2.931-4.869) } & 1 & \\
\hline \multirow{2}{*}{ ECOG PST } & 0-1 (n=99) & 5.9(4.526-7.223) & $<0.001$ & $0.495(0.267-0.796)$ & $<0.001$ \\
\hline & $2(n=39)$ & \multicolumn{2}{|l|}{$3.1(2.923-3.479)$} & \multicolumn{2}{|l|}{1} \\
\hline \multirow{2}{*}{ Tumor nodules } & single $(n=65)$ & \multicolumn{2}{|l|}{$6.6(3.225-8.987)$} & 1 & \\
\hline & multiple $(n=73)$ & $3.5(2.945-5.003)$ & 0.04 & 1.202(0.903-1.406) & 0.1 \\
\hline \multirow{3}{*}{ Tumor diameter } & $\leq 5 \mathrm{~cm}(\mathrm{n}=26)$ & $5.5(0.003-10.997)$ & $<0.001$ & $0.452(0.258-0.794)$ & $<0.001$ \\
\hline & $5-10 \mathrm{~cm}(\mathrm{n}=58)$ & 6.2(5.240-7.16) & & $0.586(0.373-0.920)$ & \\
\hline & $>10 \mathrm{~cm}(\mathrm{n}=54)$ & \multicolumn{2}{|l|}{$2.4(1.886-2.914)$} & 1 & \\
\hline \multirow{2}{*}{$\begin{array}{l}\text { Tumor } \\
\text { distribution }\end{array}$} & Monolobar $(\mathrm{n}=83)$ & 5.6(4.265-6.935) & $<0.001$ & 0.584(0.383-0.892) & $<0.001$ \\
\hline & Bilobar $(n=55)$ & $3(2.318-3.682)$ & & 1 & \\
\hline \multirow{2}{*}{ AFP } & $\leq 400 \mathrm{ng} / \mathrm{ml}(\mathrm{n}=49)$ & $5.4(4.6-6.2)$ & 0.09 & $0.672(0.429-1.051)$ & 0.1 \\
\hline & $>400 \mathrm{ng} / \mathrm{ml}(\mathrm{n}=89)$ & $3.5(2.853-4.147)$ & & 1 & \\
\hline \multirow{2}{*}{$\begin{array}{l}\text { Treatment } \\
\text { option }\end{array}$} & Palliative $(n=74)$ & $3.0(2.719-3.281)$ & 0.003 & 1 & \\
\hline & GKR $(n=64)$ & \multicolumn{2}{|l|}{$6.1(4.706-7.494)$} & $0.538(0.356-0.814)$ & $<0.001$ \\
\hline
\end{tabular}

$\boldsymbol{P}<0.05$ was considered statistically significant. All statistical analyses were conducted using SPSS 17.0 (SPSS 17.0 for Windows, SPSS, Chicago, III). GKR: gamma knife radiosurgery; PVTT: portal vein tumor thrombosis; PV: portal vein; HBV: hepatitis B virus; HCV: hepatitis C virus; ECOG: Eastern Cooperative Oncology Group; INR: international normalized ratio; AFP: alpha fetal protein.

liver function impairment in 3 months post-procedure (evidenced by elevations in alanine transaminase [ALT], aspartate transaminase $[\mathrm{AST}]$, total bilirubin $[\mathrm{TB}]$ and gamma-glutamyl transpeptidase [GTT]) (Table 3). No deaths within 4 weeks post-procedure were attributable to GKR-related AEs.

\section{Survival analyses}

Only 3 patients were still alive by the last follow-up (December $20^{\text {th }}$ 2014). The median overall survival (OS) of patients in the palliative and GKR group were 3.0 months
(95\% CI: 2.719-3.281) and 6.1 months (95\% CI: 4.706$7.494)$ respectively $(p=0.003)$ (Figure 2 , Table 4$)$. On multivariate analysis (Table 4), GKR showed significant survival benefit (hazards ratio [HR], 0.538; 95\%CI, $0.356-0.814 ; p<0.001)$ versus palliative treatment. Besides GKR treatment, PST 0-1 (HR: 0.495 ; 95\%CI: $0.267-0.796 ; p<0.001$ ), Child A (HR: $0.534 ; 95 \% \mathrm{CI}$ : $0.333-0.857 ; p<0.001)$, tumor diameter $\leq 5 \mathrm{~cm}$ (HR: 0.452; 95\%CI: 0.258-0.794; $p<0.001)$ and monolobar distribution (HR: $0.584 ; 95 \% \mathrm{CI}: 0.383-0.892 ; p<0.001$ ) were significant favorable prognosticators of OS relative to PST 2, Child B7, tumor diameter $>10 \mathrm{~cm}$ and bilobar distribution, respectively (Table 4). Subgroup (stratified by 
PVTT location) multivariate analyses showed that GKR produced survival benefits both in patients with branch of PVTT (HR: 0.634; 95\% CI: 0.393-0.961; $p=0.041$ ) and in patients with main PVTT (HR: $0.389 ; 95 \% \mathrm{CI}: 0.227-$ $0.561 ; p=0.018)$.

Multivariate analysis in the GKR group showed that Child A (HR: 0.386; 95\% CI: 0.196-0.758; $p=0.006$ ), PST 0-1 (HR: 0.412; 95\% CI: 0.209-0.791; $p=0.014$ ) and $\mathrm{AFP} \leq 400$ (HR: 0.477; 95\% CI: 0.276-0.823; $p=$ 0.008 ) were significant favorable prognosticators of OS relative to Child B7, PST 2 and AFP $>400$, respectively. (Supplementary table 1).

\section{DISCUSSION}

The treatment of HCC patients complicated with PVTT has long been a crux in the clinic. In this retrospective study, we for the first time investigate the safety and efficiency of GKR monotherapy in treating HCC-PVTT patients.

Although a substantial part of patients receiving GKR treatment experienced procedure-related AEs (Tables 2 and 3), these AEs were predominantly mild to moderate and were easily controlled with medication or subsided naturally. Only a small proportion of patients experienced severe AEs and none of them led to patient death. These results indicate that GKR can be well tolerated in selected HCC-PVTT patients as in our study.

Survival analyses revealed that GKR provided a 3.1-month survival benefit relative to palliative treatment (Figure 2, Table 4), which is comparable to the effect of sorafenib in advanced HCC patients [9, 10]. Moreover, GKR showed OS benefit in both patients with main PVTT and patients with branch of PVTT. Besides treatment option, factors that impacted OS in our study included ECOG PST, Child score and tumor characteristics (size and distribution), which is in line with the results of many similar studies [17-19]. Interestingly, patients with branch of PVTT had significantly longer median OS compared to patients with main PVTT upon univariate analysis (6 versus 3.2 months, $p<0.001$ ), whereas on multivariate analysis, PVTT location has no significant impact on OS (HR: 0.887; 95\%CI: 0.573-1.372; $p=0.6$ ). Logistic regression revealed that the presence of main PVTT was significantly correlated with larger tumor size and bilobar tumor distribution (data not shown), indicating that it is larger tumor size and bilobar tumor distribution that rendered patients more prone to developing main PVTT and bearing a worse prognosis.

Although this study is retrospective in nature, which is its main limitation, it possesses several strengths. Firstly, as Changhai Hospital (Shanghai, China) is one of the best liver cancer treatment centers in China, we have enough patients meeting the including criteria. The total number of patients enrolled in this study was more than one hundred and there was no significant difference in baseline characteristics between the two groups. Secondly, we have a palliative group as a control comprising more than 70 patients who received palliative treatment only. We have complete data on their OS though their AEs data were incomplete. This group served as the basis for OS benefit analyses of GKR treatment. And thirdly, the follow-up period of this study spanned 4 years (from January $01^{\text {st }}$, 2010 , the initiation of this study, to December $20^{\text {th }} 2014$, the last follow-up) and the vast majority of participants were followed up successfully (Figure 1). Given that the treatment allocation of HCC with PVTT is influenced by many factors such as patients' will, general condition, liver function, tumor status, economic status and complicated diseases, it is rather challenging to conduct a randomized perspective clinical trial on this regard. Therefore, this retrospective study provides valuable information on the safety and efficacy of GKR monotherapy in treating HCCPVTT.

Another limitation of this study is the lack a sorafenib-treatment only group to enable direct comparison of sorafenib and GKR. Recent studies [20-25] have investigated the efficacy of sorafenib combined with other therapeutic strategies such as TACE, radiofrequency ablation and radiotherapy on HCC-PVTT patients. It is meaningful to conduct similar studies in the future to compare GKR with sorafenib or to explore whether the two therapies can be used concomitantly.

In conclusion, this retrospective study provides the first evidence of the tolerability and efficacy of GKR monotherapy in treating HCC with PVTT, which has been practiced in China for several years. Our results indicate that GKR monotherapy are generally well tolerated and can confer survival gain in selected HCC-PVTT patients as in our study. Future perspective studies are needed to validate these results and to determine whether GKR can be recommended as a therapeutic option for HCC-PVTT patients.

\section{MATERIALS AND METHODS}

\section{Study design and patents enrollment}

Institutional Ethics Committee of Changhai Hospital (Shanghai, China) approved this retrospective study. The diagnoses of HCC were confirmed either by typical imaging manifestations or by biopsy according to recommendations by the European Association For The Study Of The Liver (EASL) [8]. PVTT was confirmed by the presence of intraluminal filling defect with an enhancement pattern similar to that of HCC on contrastenhanced computed tomography (CT) and/or magnetic resonance imaging (MRI).

The medical records of HCC patients admitted to Changhai Hospital (Shanghai, China) between January 
$01^{\text {st }}, 2010$ and December 31 $1^{\text {st }}, 2011$ were reviewed. Patients inclusion criteria: 1) HCC patients with confirmed PVTT between age 18 and 75 who were treatment-naïve when admitted to Changhai Hospital; 2) ECOG (Eastern Cooperative Oncology Group) performance status (PST): 0-2; 3) Child-Pugh score 5-7; 4) Adequate hematologic (granulocyte count $>1.5 \times 10^{9} / \mathrm{L}$, platelets $>50 \times 10^{9} / \mathrm{L}$ ) and renal (creatinine $<2.0 \mathrm{mg} / \mathrm{dL}$ ) functions; 5) Received palliative treatment alone or in combination with GKR. Patients exclusion criteria:1) Patients who received anticancer treatment other than GKR, such as hepatic resection, sorafenib, radiofrequency ablation and TACE, or anticancer treatment outside Changhai Hospital (Shanghai, China); 2) Patients with hepatic vein or inferior vein invasion, extrahepatic metastases, or malignancies of other tissue-of-origin; 3) Patients with signs of decompensated cirrhosis such as clinical hepatic encephalopathy and refractory ascites; 4) Lack of necessary parameters for subsequent analyses; 5) Patients who received more than one episode of GKR.

\section{Treatment procedures}

For each patient, treatments were allocated based upon patient will and clinicopathological characteristics, which were assessed by the HCC Expert Team in Changhai Hospital. This team comprised oncologists, hepatologists, interventional radiologists and radiation oncologists. Written informed consent was obtained from each patient prior to GKR.

Palliative treatments referred to symptomatic treatment or supportive care that aimed mainly at alleviating patients' symptoms and improving their quality of life. Patients who received palliative treatments only were allocated to palliative group. It should be noticed that patients in the GKR group also received palliative treatment.

GKR procedure: Patient was immobilized with vacuum bags in the supine position with the arms raised above the head during simulation. GTV was delineated by contrast-enhanced MRI or CT scan, which included both tumor thrombosis and the primary tumor in the liver. If the primary tumor in the liver was close to tumor thrombosis, they were included into one entire target region. If the primary lesion was far away from the tumor thrombosis or if there were multiple lesions, they were then included into different target regions. The planning target volume (PTV) was defined as a 5-10 $\mathrm{mm}$ margin around the gross tumor volume (GTV) with the aid of Treatment Planning System (TPS, OUR New Medical Technologies Co. Ltd., Shenzhen, China). The median tumor margin dose was 40 Gy (ranging from 35 to $45 \mathrm{~Gy}$ ), with a median isodose line of $55 \%(50 \%-60 \%)$. The dose prescription was limited by adjacent normal tissue tolerances and the volume of liver that could be spared (at least 1/3 of the liver volume should be spared). In brief, the liver and adjacent normal tissues (for example, gastrointestinal tract, kidney and spinal cords) were delineated during the target planning process. Dose-volume histograms were harnessed to ensure that normal tissue tolerances were not exceeded. GKS was performed with Gamma Master Space Body Knife System (also called OUR-QGD system, OUR New Medical Technologies Co. Ltd., Shenzhen, China), which is a stereotactic body radiotherapy system. The total dose of gamma knife radiotherapy was carried out in 10-12 days (five consecutive days per week).

\section{Patient follow-up and data collection}

According to the institutional protocol, regular clinical follow-ups are mandatory for all HCC patients admitted to Changhai Hospital. The vast majority of patients in the GKR groups adhered to this policy, whereas a substantial proportion of patients in the palliative group failed to do so. Clinical follow-ups were carried out 1 month after GKR and every 2 months thereafter, including detailed history and physical examinations, contrast-enhanced CT or MRI, and a complete panel of blood chemistry. GKR-related adverse events (AEs) were recorded until 3 months post-GKR according to National Cancer Institute Common Terminology Criteria for Adverse Events (CTCAE) v3.0 [16]. Survival was calculated from the day of the baseline evaluation to the day of death (confirmed by medical records or by family members).

\section{Statistical analyses}

Intergroup differences in baseline characteristics were analyzed using t-test for continuous data and ChiSquare test or Fisher exact test (for small samples) for categorical variables. Intragroup differences in LAEs between baseline and month 3 were analyzed with Exact McNemar's test. Median overall survival (mOS) was calculated using the Kaplan-Meier method and compared by the log-rank test. Variables with $P$ values $<0.25$ on univariate analyses were included in multivariate analysis (Cox proportional hazards model). $P<0.05$ was considered statistically significant.

\section{CONFLICTS OF INTEREST}

\section{None}

\section{FUNDING}

This research is funded by Key Disciplines Group Construction Project of Pudong Health Bureau of Shanghai (PWZxq2014-04). 


\section{REFERENCES}

1. Torre LA, Bray F, Siegel RL, Ferlay J, Lortet-Tieulent J, Jemal A. Global cancer statistics, 2012. CA Cancer J Clin 2015;65:87-108

2. Minagawa M, Makuuchi M. Treatment of hepatocellular carcinoma accompanied by portal vein tumor thrombus. World J Gastroenterol 2006;12:7561-7567.

3. Llovet JM, Bustamante J, Castells A, Vilana R, Ayuso Mdel C, Sala M, Brú C, Rodés J, Bruix J. Natural history of untreated nonsurgical hepatocellular carcinoma: rationale for the design and evaluation of therapeutic trials. Hepatology 1999;29:62-67.

4. Pirisi M, Avellini C, Fabris C, Scott C, Bardus P, Soardo G, Beltrami CA, Bartoli E. Portal vein thrombosis in hepatocellular carcinoma: age and sex distribution in an autopsy study. J Cancer Res Clin Oncol 1998;124:397-400.

5. Forner A, Reig ME, de Lope CR, Bruix J. Current strategy for staging and treatment: the BCLC update and future prospects. Semin Liver Dis 2010;30:61-74.

6. Lee HS, Kim JS, Choi IJ, Chung JW, Park JH, Kim CY. The safety and efficacy of transcatheter arterial chemoembolization in the treatment of patients with hepatocellular carcinoma and main portal vein obstruction. A prospective controlled study. Cancer1997;79(11):2087-2094.

7. Zhang Y, Fan W, Zhu K, Lu L, Fu S, Huang J, Wang Y, Yang J, Huang Y, Yao W, Li J. Sorafenib continuation or discontinuation in patients with unresectable hepatocellular carcinoma after a complete response. Oncotarget 2015;6:24550-59. doi: 10.18632/oncotarget.4076.

8. European Association For The Study Of The Liver; European Organisation For Research And Treatment Of Cancer. EASL-EORTC clinical practice guidelines: management of hepatocellular carcinoma. J Hepatol 2012;56:908-43.

9. Llovet JM, Ricci S, Mazzaferro V, Hilgard P, Gane E, Blanc JF, de Oliveira AC, Santoro A, Raoul JL, Forner A, Schwartz M, Porta C, Zeuzem S, Bolondi L, Greten TF, Galle PR, Seitz JF, Borbath I, Häussinger D, Giannaris T, Shan M, Moscovici M, Voliotis D, Bruix J; SHARP Investigators Study Group. Sorafenib in advanced hepatocellular carcinoma. N Engl J Med. 2008;359:378-90.

10. Bruix J, Raoul JL, Sherman M, Mazzaferro V, Bolondi L, Craxi A, Galle PR, Santoro A, Beaugrand M, Sangiovanni A, Porta C, Gerken G, Marrero JA, Nadel A, Shan M, Moscovici M, Voliotis D, Llovet JM. Efficacy and safety of sorafenib in patients with advanced hepatocellular carcinoma: subanalyses of a phase III trial. J Hepatol. 2012;57:821-9.

11. Raoul JL, Guyader D, Bretagne JF, Heautot JF, Duvauferrier R, Bourguet P, Bekhechi D, Deugnier YM, Gosselin M. Prospective randomized trial of chemoembolization versus intraarterial injection of 131I-labeled-iodized oil in the treatment of hepatocellular carcinoma. Hepatology 1997;26:1156-1161.

12. Sangro B, Carpanese L, Cianni R, Golfieri R, Gasparini D, Ezziddin S, Paprottka PM, Fiore F, Van Buskirk M, Bilbao JI, Ettorre GM, Salvatori R, Giampalma E, Geatti O, Wilhelm K, Hoffmann RT, Izzo F, Iñarrairaegui M, Maini CL, Urigo C, Cappelli A, Vit A, Ahmadzadehfar H, Jakobs TF, Lastoria S; European Network on Radioembolization with Yttrium-90 Resin Microspheres (ENRY). Survival after yttrium-90 resin microsphere radioembolization of hepatocellular carcinoma across Barcelonaclinic liver cancer stages: a European evaluation. Hepatology 2011;54:868-78.

13. Park ES, Kwon do H, Park JB, Lee do H, Cho YH, Kim JH, Kim CJ. Gamma Knife surgery for treating brain metastases arising from hepatocellular carcinomas. J Neurosurg. 2014;121 Suppl:102-9.

14. Xu Q, Wu P, Feng Y, Ye K, Tong Y, Zhou Y. Gamma knife surgery for brain metastasis from hepatocellular carcinoma. PLoS One 2014;9:e88317.

15. Lu XJ, Dong J, Ji LJ, Luo JH, Cao HM, Zhou J, Ling CQ. Safety and efficacy of TACE and gamma knife on hepatocellular carcinoma with portal vein invasion. Gut 2015 doi:10.1136/gutjnl-2015-310292 [Epub ahead of print].

16. http://ctep.cancer.gov/protocolDevelopment/electronic applications/ctc.htm

17. Cabibbo G, Enea M, Attanasio M, Bruix J, Craxì A, Cammà C. A meta-analysis of survival rates of untreated patients in randomized clinical trials of hepatocellular carcinoma. Hepatology 2010;51:1274-83.

18. Golfieri R, Bilbao JI, Carpanese L, Cianni R, Gasparini D, Ezziddin S, Paprottka PM, Fiore F, Cappelli A, Rodriguez M, Ettorre GM, Saltarelli A, Geatti O, Ahmadzadehfar H, Haug AR, Izzo F, Giampalma E, Sangro B, Pizzi G, Notarianni E, Vit A, Wilhelm K, Jakobs TF, Lastoria S; European Network on Radioembolization with Yttrium-90 Microspheres (ENRY) study collaborators. Comparison of the survival and tolerability of radioembolization in elderly vs. younger patients with unresectable hepatocellular carcinoma. J Hepatol 2013;59:753-61.

19. Sangro B, Carpanese L, Cianni R, Golfieri R, Gasparini D, Ezziddin S, Paprottka PM, Fiore F, Van Buskirk M, Bilbao JI, Ettorre GM, Salvatori R, Giampalma E, Geatti $\mathrm{O}$, Wilhelm K, Hoffmann RT, Izzo F, Iñarrairaegui M, Maini CL, Urigo C, Cappelli A, Vit A, Ahmadzadehfar $\mathrm{H}$, Jakobs TF, Lastoria S; European Network on Radioembolization with Yttrium-90 Resin Microspheres (ENRY). Survival after yttrium-90 resin microsphere radioembolization of hepatocellular carcinoma across Barcelona clinic liver cancer stages: a European evaluation. Hepatology2011;54:868-78.

20. Zhu K, Chen J, Lai L, Meng X, Zhou B, Huang W, Cai M, Shan H. Hepatocellular carcinoma with portal vein tumor thrombus: treatment with transarterial chemoembolization 
combined with sorafenib - a retrospective controlled study. Radiology 2014;272:284-93.

21. Hu H, Duan Z, Long X, Hertzanu Y, Shi H, Liu S, Yang Z. Sorafenib combined with transarterial chemoembolization versus transarterial chemoembolization alone for advancedstage hepatocellular carcinoma: a propensity score matching study. PLoS One 2014;9:e96620.

22. Choi GH, Shim JH, Kim MJ, Ryu MH, Ryoo BY, Kang YK, Shin YM, Kim KM, Lim YS, Lee HC. Sorafenib alone versus sorafenib combined with transarterial chemoembolization for advanced-stage hepatocellular carcinoma: results of propensity score analyses. Radiology 2013;269:603-11.

23. Zhu K, Chen J, Lai L, Meng X, Zhou B, Huang W, Cai M, Shan H. Hepatocellular carcinoma with portal vein tumor thrombus: treatment with transarterial chemoembolization combined with sorafenib - a retrospective controlled study. Radiology 2014;272:284-93.

24. Cho JY, Paik YH, Park HC, Yu JI, Sohn W, Gwak GY, Choi MS, Lee JH, Koh KC, Paik SW, Yoo BC.The feasibility of combined transcatheter arterial chemoembolization and radiotherapy for advanced hepatocellular carcinoma. Liver Int 2014;34:795-801.

25. Li Y, Zheng YB, Zhao W, Liu B, Hu BS, He X, Huang JW, Lu LG. Sorafenib in combination with transarterial chemoembolization and radiofrequency ablation in the treatment for unresectable hepatocellular carcinoma. Med Oncol 2013;30:730. 